\title{
ON THE NORTH AMERICAN SPECIES OF SIPHONELLA.
}

BY C. F. ADAMS, CHICAGO, ILL.

Baron Osten-Sacken in his Catalogue listed five species in this genus, placing plumbella IVied. therein on the authority of Loew. After a study of type material Mr. Coquillett has removed obesa Fitch, placing it as a synonym of Chlorops assimilis Macq. In material which I have studied I have recognized two European species and three new ones. Several specimens of $S$. laevigata Fall. were collected by Dr. Hough at New Bedford, Mass., and one specimen of S. trilineata Meig. comes from Colorado. The species appearing under the name nigrirostra comes from Grenada, IV. I., and is one of several Diptera worked out by Dr. Williston and myself for the British Museum. The manuscript is not yet published, but the species is sufficiently characterized, for the present paper, in the following table:-

Table to the Species. ${ }^{1}$

I. Thorax vittate Thorax not vittate

2. Antennae wholly yellow Antennae at least with tip infuscated

3. Halteres brownish black Halteres yellow

4. Mesonotum with three lines. Mesonotum with five lines

5. The mesonotal lines consist of shallow sulci . The mesonotal lines consist of brown colored vittae

6. Thorax pollinose . Thorax shining

7. Antennae largely black Antennae largely yellow

8. Face yellow . Face black .

9. Anterior and middle tibiae largely black Anterior and middle tibiae yellow cinerea Loew. inquilina Coq. laevigata Fall. nigrirostra Adams.

\footnotetext{
1 After this paper nad gone to press I noticed that Dr. J. B. Smithin his "Insects of New Jersey," page 696, has reported Siphonella pumitionis Bjerk. from Riverton, N. J. After examining specimens of this species I find that it will stand next to quinquelineata in the table, and will be known from it by having the thorax yellow, marked with black vittae, instead of black, marked with brown vittae.
} 
Siphonella parva n. sp.

Upper half of front, and occiput black, with gray pollen; lower half of front, antennae except tip of third joint, face, cheeks, and palpi yellow, proboscis black. Thorax gray pollinose, short pile yellowish white, mesonotum with three indistinct, shallow sulci; halteres yellow. Hind margins of abdominal segments yellowish. Legs yellow, all femora, and hind tibiae blackish centrally. Wings hyaline, third and fourth veins parallel. Length $\mathrm{r} .5 \mathrm{~mm}$.

One specimen. Colorado.

\section{Siphonella quinquelineata $\mathrm{n}$. sp.}

Black, gray pollinose, mesonotum marked with five brown lines. Occiput, frontal triangle, and frontal orbits grayish pollinose; front brownish black, anterior margin and a median line fulvous; antennae brownish black, inner sides of joints yellowish, face, cheeks, and palpi yellow, proboscis with basal half black, apical half yellow. The two lateral vittae of the mesonotum short and very indistinct, the very short pile yellowish white; haiteres yellow. Abdomen brownish black, posterior margins of segments yellowish. Legs with coxae, femora, and middle and hind tibiae largely black, remaining parts yellow. Wings hyaline. Length $1.7 \mathrm{~mm}$.

Four specimens, Opelousas, La., and Tipton, Ga. April, June, and October.

Chryptorhynchus iapathi in Minnesota.-In view of Mr. Kirkland's article in Psyche, Vol. 8, p. 37, June, 1899 , in which he describes the finding of this introduced beetle in Balm of Gilead poplar in Massachusetts, it may interest the readers of Psyche to know that we have found it here this last spring, illustrating the steady westward progress of this unwelcome immigrant. Burgess found it in Ohio a few years ago. Cooley of Montana reports seeing ONE specimen in 1899 in Montana. It was brought here and from here sent away up into the northwestern corner of North Dakota, in a shipment of nursery stock (Carolina Poplars) from New York State. - F. L. Washburn, St. Anthony Park, Minn., Sept. 29, I904. 

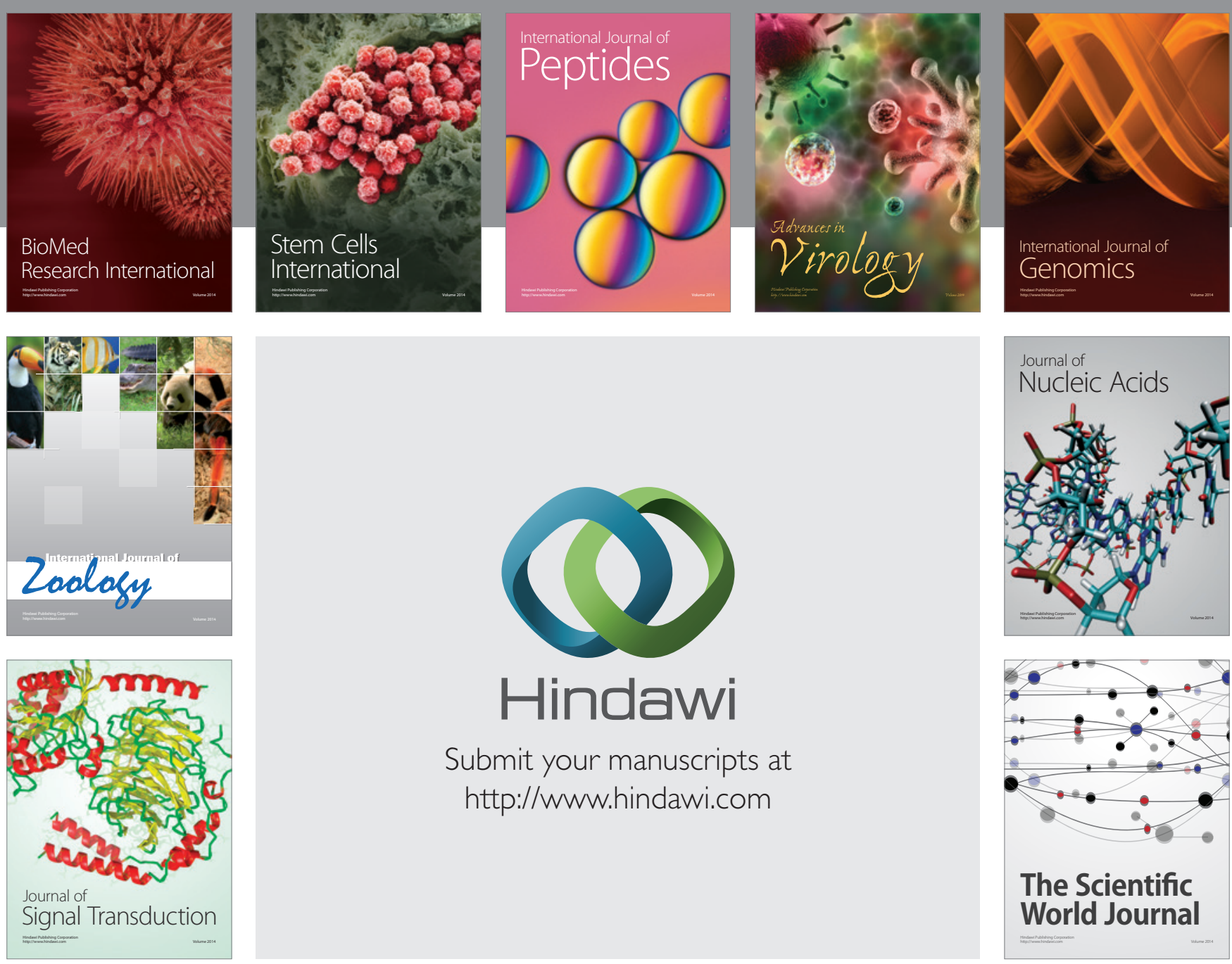

Submit your manuscripts at

http://www.hindawi.com
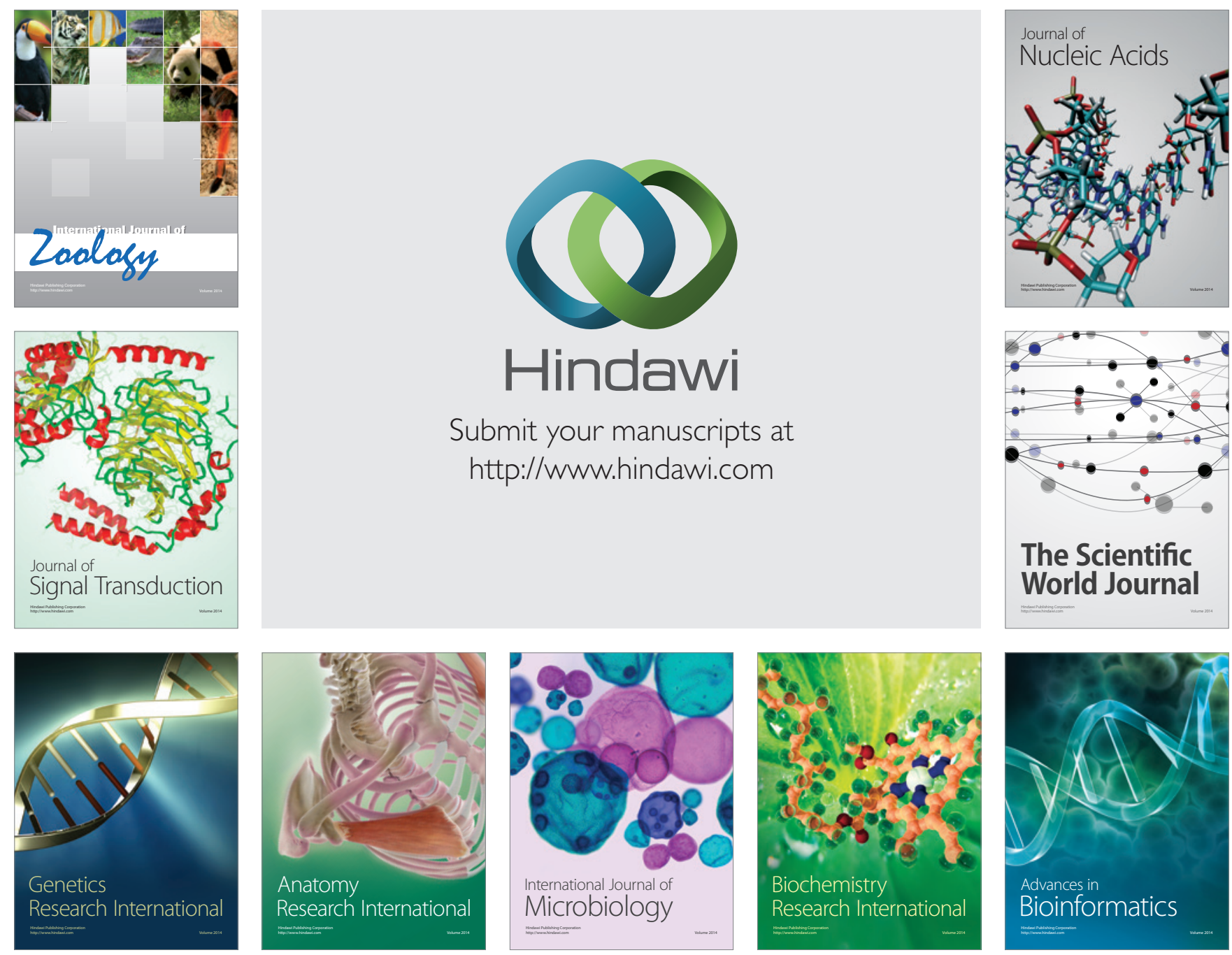

The Scientific World Journal
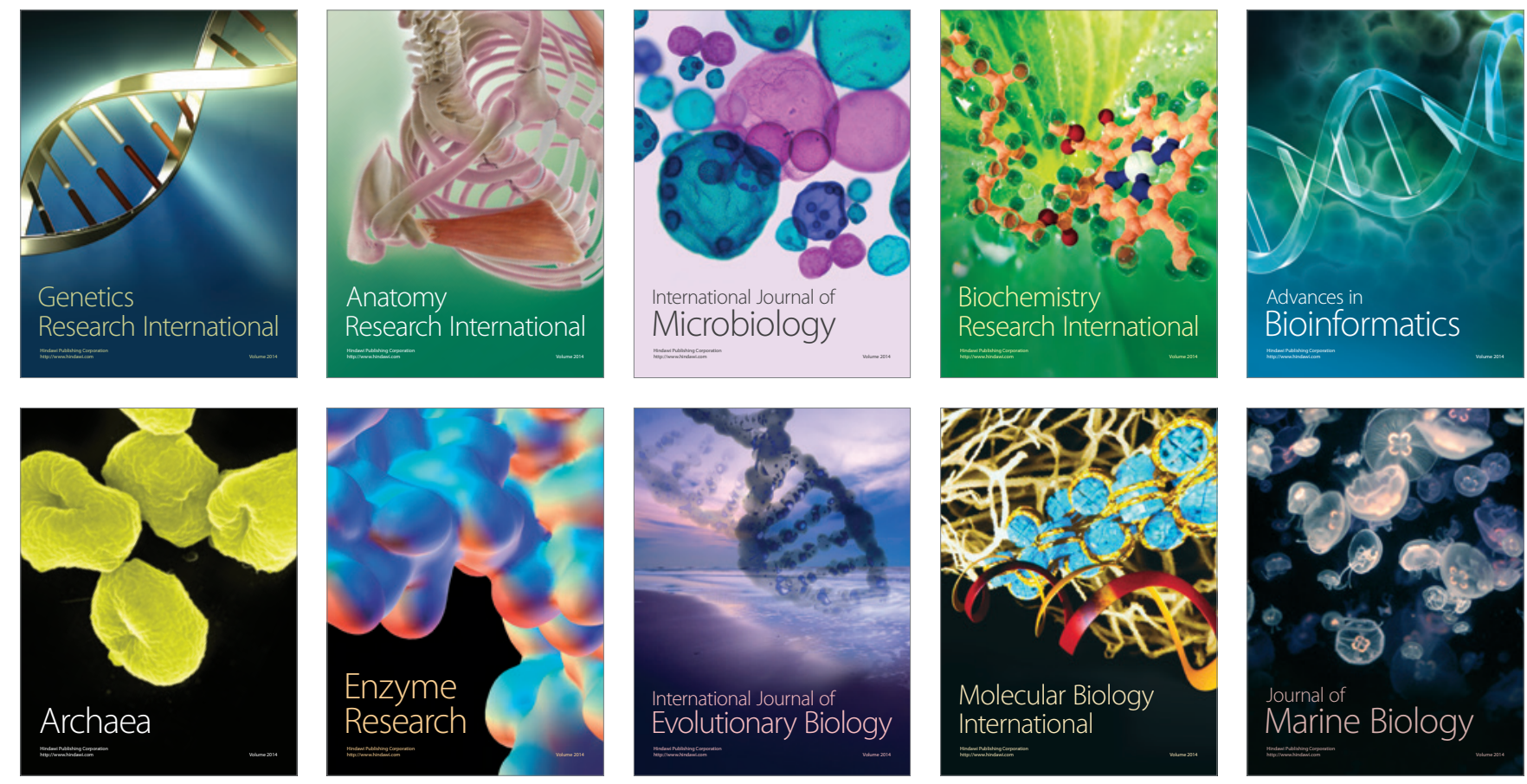